\title{
Balance Analysis Of Dust Over Onus Backfill Structure Victimization Physical Create Skill
}

\author{
Prof. Kamal Reddy, Prof. Avinash Reddy \\ Dept Of Civil Engineering Jain University, Bangalore, India
}

\begin{abstract}
Thanks to quickly growing energy desires and therefore the resultant rise within the use of coal to fulfill them, exploration and exploitation of coal resources has seen exponential growth. world considerations concerning the environmental impact of coal exploitation have LED to AN increasing shift to open-cast mining of coal, in situ of the normal deep-pit mining. This has LED to go looking for an appropriate technique of handling the big amount of soil - termed overonus that's a by-product of open-cast coal mining. the foremost sensible technique of disposal of overonus has been to dump it in close open areas, that causes concern concerning the soundness and mechanical behavior of the resultant hillocks. This was followed by a field study, conducted to determine the muse characteristics of the soil at the external dumps of the open-cast mines. Samples of soil were procured from the open-cast mines and subjected to laboratory study for evaluating the physico-mechanical and geo-technical characteristics of soil for crucial varied attributes like relative density, bulk density, porosity, permeableness, granulometric distribution of various size fractions, Atterburg's limit, cohesion, angle of internal friction, CA bearing quantitative relation etc. Numerical create was then conducted to see the structural stability of dump configuration on the premise of knowledge obtained from laboratory studies. Lastly, field trials were dispensed victimization physical create, to guage dump stability once backfilling victimization AN admixture of pool dust and overonus.
\end{abstract}

Keywords- Open-Cast Mining, Physico-Mechanical, Physical Create, Pond Dust, Overonus. 


\section{Introduction}

The ability sector in India is dominated by coal. Coal presently accounts for over five hundredth of total primary industrial energy provide within the country and for concerning seventieth of total electricity generation. Coal is probably going to stay a key energy supply for India, for a minimum of consecutive few decades, as India has important domestic coal resources (relative to different fossil fuels) and an outsized set of existing put in base of coal-based electricity capability, though recent experiences have thrown into sharp relief the uncertainties and considerations relating to the adequacy of coal provides to satisfy the growing hunger for power.

\section{Sample}

assortment a close survey of the dust pool of RSTPS, NTPC was dispensed before rise pool dust samples for scientific investigation. to get representative samples of pool dust, AN excavation of $1 \mathrm{~m} \times 1 \mathrm{~m}$ cross-sectional up to $1 \mathrm{~m}$ depth was created and therefore the excavated dust was completely mixed and one bag (30 Kgs aprox.) proportional sample was taken when coning and quartering from every purpose. A survey of external overonus dumps of Medapalli opencut was conjointly dispensed and representative samples of soil and overonus material were collected from all the external dumps. a complete of vi bag samples of overonus material and a pair of bag samples of soil were collected.

\section{Methodology}

The methodology adopted to accomplish the target of the project is given below in written account manner:

(a) Sample assortment (b) Laboratory study to guage the physico-mechanical/ geotechnical characteristics of pool dust and overonus material which incorporates determination of relative density, bulk density, porosity, permeableness, granulometric distribution of various size 


\section{THE AMERICAN JOURNAL OF APPLIED}

\section{SCIENCES}

\section{VOLUME01 ISSUE05}

fractions, Atterburg's limit, cohesion, angle of internal friction, CA bearing quantitative relation etc.

(b) Field knowledge assortment relating to mining details, geology, downfall pattern, spring water conditions etc.

(c) Field study to see the muse characteristics of the soil at the external dumps of opencut Mines.

(d) Numerical create to see the structural stability of dump configuration/stability with pool dust and overonus on the premise of knowledge obtained throughout laboratory studies.

(e) Field trials to hold out physical create to guage dumb stability once backfilling with pool dust overonus admixture.

\section{Physical Characteristics}

The physical characteristics of dust depend upon the quality/rank of coal used, degree of pulverization, chamber temperature, its chemical composition etc. Similarly, physical characteristics of overonus area unit principally influenced by the earth science of the world, mining technique adopted, general topography etcmine are found to be greatly influenced by physical characteristics viz., relative density, bulk density, porosity, angle of repose, permeableness, softness, granulometric distribution and different geotechnical parameters.

\section{Undersoil Characterization}

Soil characterization and classification is of utmost importance once handling engineering issues because it act as a language of communication. Classification of soil can facilitate grading them to be used for specific engineering project per their advantage. For this, soil core samples were collected from three boreholes (BH three, $\mathrm{BH}$ four and $\mathrm{BH} 5$ ) trained close to Dump yard No.3 and a pair of throughout previous study dispensed at MOCP. 


\section{Topography Emptying And Downfall}

The area forms the southern bank of the Godavari watercourse and is characterised by flat to carefully undulating tract with general elevation variable from $130 \mathrm{~m}$ to $140 \mathrm{~m}$ on top of mean water level with a delicate slope towards south East. watercourse Godavari forming North japanese boundary of the block, drains the world beside its transitory tributaries. the very best Flood Level of Godavari watercourse was recorded as $138.55 \mathrm{~m}$ on top of MSL (Corresponding to $838.55 \mathrm{~m}$ of assumed Level) throughout the monsoon on twenty.10.1995. giant portion of the block is roofed underneath this HFL of the watercourse.

\section{Result And Discussion}

From the results of laboratory investigation, physical create and model study dispensed in field, following inferences and proposals is drawn.

The particular gravity of RSTPS pool dust has been found to be one.99, which suggests that it's concerning twenty seventh lighter than overonus (Avg. Sp.Gravity 2.54) thus the energy demand for its transportation by any suggests that (mechanical or hydraulic) are going to be less. the majority density of dust overonus admixture was found to decrease with the rise in proportion of pool dust content and so it becomes constant at four-hundredth pool dust. this means that with the rise in dust content the density and so the strength of backfill admixture decreases. This conjointly indicates that a lot of volume of dust-overonus admixture is hold on in pre-defined space compared with overonus alone.

From the grain size analysis it had been found that nineteen. $2 \%$ of overonus proportional sample and 9/11 of pool dust particles area unit below 106 micrometer size and fines (< twenty microns) area unit found to be a pair of for overonus and three. $2 \%$ for pool dust underneath scrutiny. The metallic element and Cc price of pool dust indicates that it's uniformly stratified, whereas for overonus samples it indicates that they're well stratified. The grain size distribution of soil samples have a flat curve, that indicates it's well stratified. A well stratified soil and can provide a lot of resistance to displacement and settlement than one with uniformly stratified particles, thus it is complete pool dust alone are going to be a lot of compressible then overonus material, foundation soil furthermore as dust - overonus admixture. ? The permeableness of water through the fill packed mass of pool dust and overonus was found to be less for over overonus 
material alone, however it had been pointed out that with the rise within the pool dust proportion within the backfill admixture the worth of " $k$ " conjointly will increase. The natural angle of repose was found to be concerning 350 for overonus material alone, however it decreases once pool dust is added to that. From the on top of observation 2 conclusions is draw, first that addition of overonus material to pool dust will increase its consistency and so is permeableness and second, there's a decrease in angle of repose of the pool dust - overonus admixture thanks to decrease in particle size gradation and so this can end in reduction in its strength characteristics. ? The Results of Liquid limit and plastic limit take a look at dispensed on overonus, pond dust, pool dust-overonus admixture in numerous proportion indicated that they're non-plastic in nature, except for soil samples it had been found that Brown loose Sand and Black Clay portion of core exhibits physical property. Direct shear take a look at results indicated that the cohesion will increase with the rise in pool dust proportion of the admixture up to half-hour that indicates that the metal content of pool dust will increase the cohesive strength of the admixture.

\section{Conclusion}

Geotechnical tests were performed for the coalpit refuse samples of various mines to guage the quality as filling material. These tests embody $\mathrm{CMB}$, customary Proctor Compaction take a look at, Direct shear take a look at, permeableness take a look at and Atterberg limits take a look at. From the results of these tests it's going to be complete that combination of dust is used for the aim of backfilling while not abundant treatment. merchandising of overonus alone is to be dispensed to confirm that the dust- $\mathrm{OB}$ admixture is completely lined and guarded from the $\mathrm{OB}$ dumps comprehensive. dimension of the $\mathrm{OB}$ dump shall not be but thirty $m$ that shall even be compacted. The benches shall be set in such a way that the slope of the dump shall not exceed 210 from horizontal

\section{References}

1. R.W., L.S. Thomas, S. Sharma and G.M. Boyce. Slope Stability and Stabilization strategies. 2000. SMU Wiley \& Sons. New York.

2. Funcan, J.M., 1990, "State of the art: limit equilibrium and finite component analysis of slopes,"Journal of Geotechnical Engineering. 
3. Dr. Cvert Hoek, sensible Rock Engineering, 2001, chpt.

4. 1983 : "Indian customary for preparation of dry soil samples for varied tests", Bureau of Indian Standards Publications.

5. PAMNNA .S.K \& Justo C.E(March 2000), Highway Engineering, Nem Chand \& Bros. 